\title{
NOTAS SOBRE A POESIA PORTUGUESA DA DÉCADA DE 70: O CASO DE AL BERTO
}

\author{
Leonardo de Barros Sasaki* \\ Universidade de São Paulo
}

Resumo: O presente artigo propõe-se a pensar, em suas linhas gerais, a lírica portuguesa contemporânea, em especial aquela produzida na década de 70, a partir do caso exemplar de $\mathrm{Al}$ Berto. Entre os temas abordados, destacam-se: a relação entre a poesia e o real; a tentativa de recuperá-lo - ainda que de forma precária ou, melhor dito, em sua própria precariedade -; o caráter declaratório e dialogante da poesia; sua dicção mais afetiva e menos virtuosista; a não-coincidência entre poema e poesia - no que se falou em "novo romantismo"; a renovada - e problemática - vinculação/constituição do sujeito poético; e a desinibição de temas mais cotidianos e libertos. Para isso, recuperam-se as leituras de críticos fundamentais não apenas para a compreensão da produção portuguesa contemporânea como também para a discussão, em paralelo, das mesmas tendências em outras tradições. Por fim, desenvolve-se especificamente a análise de dois poemas de Al Berto, a fim de melhor demonstrar a discussão teórica suscitada.

Palavras-chave: Poesia portuguesa contemporânea. Al Berto. Real. Subjetividade. Afetos

\section{Introdução (com menção a Poesia 61)}

É consenso na crítica portuguesa o lugar destacado da obra do poeta contemporâneo Al Berto (1948-1997) no contexto da década de setenta e oitenta e sua influência decisiva nas gerações subsequentes (AMARAL, 1991; BARRENTO, 2000; COELHO, 1988; GUIMARÃES, 2002; MARTELO, 2007). Nuno Júdice, leitor pouco dado a hipérboles, chega a sentenciar: "o que fica é o homem que soube impor o seu lugar, e se mantém como o último grande poeta do século XX" (JÚDICE, 2007, p. 69). Assim sendo, como objetivo global, propomos estudar o caso de Al Berto demostrando, em linhas gerais, de que forma nele se manifestam as preocupações, tensões e deslocamentos da poesia portuguesa da década de 70.

\section{$\Theta \oplus \Theta \Theta$}

BY NG ND Esta obra está licenciada sob uma Licença Creative Commons.

\footnotetext{
* Doutorando em Literatura Portuguesa pela Universidade de São Paulo (USP), com bolsa da Fundação de Amparo à Pesquisa do Estado de São Paulo (FAPESP) sob orientação da Profa. Dra. Annie Gisele Fernandes. Mestre em Literatura Portuguesa (2012) pela mesma instituição. Obteve bolsa (BEPE/FAPESP) para realização de estágio de pesquisa na Biblioteca Nacional de Portugal e na Universidade do Porto sob orientação da Profa. Dra. Rosa Maria Martelo. É editor-responsável da Revista Desassossego (USP) desde 2011. É membro dos Grupos de Estudo "Poéticas e Estéticas da Modernidade" (USP) e "Poesia Moderna e Contemporânea" (UFMG); e membro-colaborador do Centro de Literaturas e Culturas Lusófonas e Europeias (Universidade de Lisboa).
} 
Nos papéis que compõem o espólio do poeta, encontram-se anotações de sua leitura de Cartas a um jovem poeta, de R. M. Rilke (E49 cx. 33) ${ }^{1}$. Dentre os trechos que lhe despertaram interesse, o poeta alemão adverte: “As obras de arte são de uma infinita solidão; nada as pode alcançar tão pouco quanto a crítica. Só o amor as pode compreender e manter e mostrar-se justo com elas" (RILKE, 1986, p. 32). Neste artigo, tendo tais observações preliminares como fio condutor, nosso esforço será refletir sobre a primazia do "amor" - ou, melhor, dos afetos - sobre uma crítica que "tão pouco alcança". Dito de outra maneira, perguntamos: em Al Berto, que implicações e protocolos estão subjacentes a essa "crítica da crítica" e a um objeto artístico que se pretende eminentemente emotivo, patêmico?

O poema de abertura de Uma existência de papel fecha-se com a seguinte quadra: "da humidade antiga do eremitério ergue-se / a sageza e a sabedoria que foi abandonando / à laboriosa travessia da vida / à lentíssima decifração do medo e dos sinais" (M, p. 505 $)^{2}$. São versos que, em nosso entendimento, exprimem uma espécie de arte poética. Essa poesia renunciou a um discurso da "sageza", o que aponta para diferentes adjetivações, salientemos, não exatamente concomitantes: sublime, abstratizante, cerebral, erudita, culturalista, textualista, etc. A obra mostra-se orientada por um vínculo mais estreito entre arte e vida ainda que esta possa apenas ser apreendida enquanto perigo, alerta e fragmentação (“do medo e dos sinais"). O labor da poesia não é aquele do "obstinado rigor" verbal, mas da mutabilidade e impermanência - visto que é "travessia" - da vivência, seus afetos e questionamentos. Como diz o autor em entrevista ao Diário de Notícias: "Continuo a ter um relacionamento com o mundo, que passa pelos afectos, do ódio à paixão, do repúdio ao espanto" (AL BERTO, 1997, p. 32; grifo nosso).

Grosso modo, esse quadro esboça os dois marcos históricos assentados pela crítica ${ }^{3}$ quando se propõe a traçar um panorama da poesia portuguesa na segunda metade do século XX. O primeiro deles seria a década de 60, com a emergência da recolha Poesia 61; o segundo, a década de 70, relacionando-o - direta ou indiretamente - à Revolução de Abril e à

\footnotetext{
1 "E49" é a identificação do espólio de Al Berto depositado na Biblioteca Nacional de Portugal. Reportamo-nos aqui ao levantamento por nós realizado e reunido no âmbito de nossa dissertação (SASAKI, 2012).

2 As citações ao trabalho poético de Al Berto, por conveniência, trarão apenas a indicação da página. As siglas "M" e "D" indicam excertos oriundos, respectivamente, da obra reunida O Medo (AL BERTO, 2009) e dos Diários (AL BERTO, 2012) recém-publicados. Ambas as referência constam da bibliografia.

${ }^{3}$ Para essa revisão bibliográfica, tomam-se autores, cujos textos de teor mais panorâmico são aqui considerados fundamentais para a compreensão da produção portuguesa contemporânea, a saber: "Tensões e deslocamentos na poesia portuguesa depois de 61" de Rosa Maria Martelo, "Um quarto de século de poesia” de João Barrento, "A poesia portuguesa do fim do século: emergências post-modernistas" de Carlos Reis, "Uma outra poesia: de João Miguel Fernandes Jorge a Al Berto" de Fernando Guimarães, "Dos anos 70 à década de 90" de Nuno Júdice, "Modernismo, modernidade e suas consequências: um percurso por alguma poesia portuguesa deste século" de Fernando Pinto do Amaral e "Dez anos de literatura portuguesa (1974-1984): poesia" de Fernando J. B Martinho. As referências constam de nossa bibliografia.
} 
publicação do Cartucho. Propomos, primeiramente, um breve excurso por esquemas analíticos, os mais abrangentes, a fim de distinguir as linhas de força características da lírica contemporânea - pensadas não como exclusivas do cenário literário português, mas integradas em limites mais alargados do campo estético contemporâneo.

O texto de Rosa Maria Martelo, em Vidro do mesmo vidro, é exemplar na busca de tensões entre as referidas vertentes poéticas - menos para detectar rupturas e mais para discutir linhas de continuidade e deslocamentos. A começar pelo grupo de 61, formado por Casimiro de Brito, Gastão Cruz, Fiama Hasse Brandão, Luiza Neto Jorge e Maria Teresa Horta, ressalta-se, sobretudo, o esmero textual e a contenção/concentração da linguagem desta produção - ou, como prefere a autora, sua "espessura discursiva” (MARTELO, 2007, p. 25). É a partir desse pendor formal que João Barrento (2000) lê essa poesia como "vigiada", "rigorosa na linguagem", "lapidada e algo fria", tendo em mente a fórmula modernista da impessoalidade da voz lírica. Fernando Guimarães, em sintonia crítica, ressalta esta "linguagem que se assume em termos de uma maior depuração e que tende para uma expressão contida e rigorosamente segmentada" (GUIMARÃES, 2002, p. 36).

Rosa Martelo, em Vidro do mesmo vidro (2007), dedica-se a explorar mais detidamente as características deste período e assim as lista - para as citações, indicamos apenas as páginas: a) a "somatização de sua relação com o mundo" (p. 26), no que concerne, como bem anota a crítica, à "sabotagem dos poderes instituídos" (p. 14) sem implicações de orientação ideológica, panfletária; b) o privilégio no emprego das imagens e no choque surpreendente entre elas - na pertinente lembrança do testemunho de Gastão Cruz: "E era de imagens que nós achávamos que a poesia vivia” (p. 24); e c) resistência à paráfrase e ao discurso cotidiano - no que tange à "exploração da linguagem poética como uma língua outra, minoritária" (p. 13) ou ainda à "desconfiança perante o efeito de realismo" (p. 25).

São esses traços que levam alguns críticos a concluir que os "anos sessenta tinham ainda estado totalmente subordinados ao espírito dos Modernismos e das vanguardas históricas" (BARRENTO, 2000). Assim concorda Martelo, para quem a poética dominante na poesia dessa década procurou "reactivar a tradição modernista" (MARTELO, 2007, p. 40).

É importante ressalvar, porém, que a autora, consoante Luís Miguel Nava, se posiciona contrariamente à ideia de que existam rupturas de poéticas e superação da modernidade - o que não significa, pelo óbvio, Modernismo - entre os períodos aqui tratados. Para ela, enquanto os de sessenta filiavam-se à linha modernista de vanguarda, os de setenta, a "uma tradição baudelairiana, uma modernidade em sentido lato" (MARTELO, 2007, p. 40). 
Fernando Pinto do Amaral, por sua vez, partindo do mesmo Nava, admite antecedentes poéticos aos de setenta - sobretudo Ruy Belo -, mas percebe "um princípio do declínio da modernidade" na ultrapassagem dos anos sessenta (AMARAL, 1991, p. 49; grifo do autor) ${ }^{4}$.

Chamemos ruptura ou deslocamento, o inescapável é apercebermo-nos das expressivas modulações, de um momento ao outro, nas opções discursivas e nos protocolos de leitura estabelecidos. É possível, nesse sentido, recuar ainda mais para se observar a que reagiu o ímpeto vanguardista da Poesia 61. Carlos Reis lembra que poetas como Gastão Cruz, Fiama Hasse Brandão e Luiza Neto Jorge tendiam a "retrair o empolamento discursivo que caracterizara alguma da poesia portuguesa das décadas anteriores, sobretudo a presencista e a neo-realista” (REIS, 2005, p. 87). O depoimento de Eduardo Prado Coelho ilustra precisamente como, a partir dessa "soma de condenações", nascia

uma enorme vontade de, com o apoio da linguística emergente e da semiótica balbuciante, e a coberto de uma teoria que se proclamava rigorosamente materialista, escrever uma poesia que fosse revolucionária, não pelo significado dos seus enunciados, mas pela estrutura de suas enunciações (COELHO, 1988, apud AMARAL, 1991, p.49; grifo nosso)

Para essa poesia, sua atitude revolucionária, sua estratégia de resistência não era temática, mas formal. Martelo chama este processo de "somatização estrutural", isto é, "por em evidência as características discursivas [do poema] e faze[r] dessas propriedades objecto de referência" (MARTELO, 2007, p. 37). Lembra a autora ainda que isso nada tem a ver com um fechamento do texto sobre si mesmo, mas antes "é uma condição de abertura, um modo de este se tornar permeável a um real que se tornou problemático e essencialmente entendido como ausência do real" (MARTELO, 2007, p. 37). Em outras palavras, o foco da poesia em sua "estrutura da enunciação" - e, portanto, o esmaecimento de uma dimensão referencial espelha uma realidade cada vez mais esvaziada de concretude.

\section{Al Berto e a geração de 70}

É justamente essa relação com o real que nos interessa por ser um dos pontos de deslocamento entre a poesia feita até a década de sessenta e a produção subsequente. A

\footnotetext{
${ }^{4} \mathrm{O}$ conceito de sobremodernidade de Marc Augé, ao qual recorre Martelo, assim como, por exemplo, o de hipermodernidade de Gilles Lipovestsky apontam para a imprecisão do termo "pós-moderno" por não vivermos exatamente, segundo esses autores, o fim da modernidade, mas a exacerbação de seus valores. De nossa parte, cabe anotar a existência de uma incompatibilidade terminológica no entendimento das - ou na tônica posta nas alterações ocorridas no mundo nestes últimos anos, mas que não estamos completamente convencidos, contudo, de que sejam posições excludentes, já que muitas percepções teóricas postuladas como "rupturas" auxiliam-nos a perceber os "deslocamentos" - entendimento que preferimos e acolhemos.
} 
publicação do Cartucho, em 1976, reuniu os que seriam nomes destacados desta geração ${ }^{5}$ : João Miguel Fernandes Jorge, António Franco Alexandre, Helder Moura Pereira e Joaquim Manuel Magalhães - este último sendo o responsável pela divisa "regresso ao real", que se converteria, como é consenso na crítica, numa espécie de moto para as poéticas desse momento. O testemunho do próprio poeta vale a citação:

Contra a necessária, na altura, rarefação do sentimento, do enunciado e do imaginário, surge na poesia mais recente um ímpeto renovado de se contar, de se assumir, por máscara ou directamente, um discurso cuja tensão é menos verbal do que explicitamente emocional. (MAGALHÃES, 1981, p. 258, grifo nosso).

Se fica patente as diferentes pulsões - uma "verbal", outra "emocional" -, é digno de consideração o reconhecimento do débito para com as conquistas da Poesia 61, o que Magalhães chama de "libertação da poesia" (MAGALHÃES, 1981, p. 257) dos modelos neorealistas - como já mencionamos anteriormente. A geração de sessenta tentou "demonstrar que era possível um discurso materialista sem o imediatismo do compromisso" (MAGALHÃES, 1981, p. 256, grifo nosso). Nesse sentido, pode-se dizer que, mesmo indiretamente, há uma contribuição, uma preparação de terreno, para que a geração posterior pudesse reativar um contato "emocional" com a realidade, isto é, criar efeitos de realismo que não estivessem constitutivamente atrelados a algum engajamento político.

O que está em jogo para esses poetas é certa reabilitação do poder referencial da linguagem, sua dimensão mais discursiva - e até mesmo prosaica. A redescoberta desse realismo, todavia, não significa encarar a produção pós-70 como um retorno da crença mimética da arte. Tal literatura é representativa de "um estado de espírito subsequente à crise da mimesis e à ruína da ideia de uma arte que imitasse a realidade" (AMARAL, 1991, p. 50). Os olhos do poeta que tornam a mirar o mundo e seu cotidiano já não têm por objetivo a imitação; estão, antes, imbuídos de um caráter pessoal, íntimo: “a realidade das coisas é perturbada ou, se se preferir, configurada pela emoção, pela afectividade ou pelos sentimentos, de modo que a realidade ganha uma configuração que acaba por vir perturbá-la, perturbando-nos" (GUIMARÃES, 2002, p. 165, grifo nosso), como disse Fernando Guimarães a respeito de António Franco Alexandre.

\footnotetext{
${ }^{5}$ O termo "geração" quando empregado não sinaliza uma coesão absoluta entre os poetas surgidos nestas balizas temporais, mas as tendências preponderantes, suas características comuns. Poderia objetar-se que há diferenças fundamentais entres os autores. Aproveitamos aqui a lição de Todorov sobre os românticos e o Romantismo: ora, não há contradição entre os que advogam pelas distinções irredutíveis e aqueles que procuram linhas de contiguidades e oposições globais com outras poéticas. Conclui Todorov: trata-se simplesmente do "grau de generalidade com que se decide operar" (1982, p. 166). O próprio Al Berto, quando fala do confessionalismo em sua obra, admite que este talvez fosse um "tique de geração" (1997, p. 32). Se não há uma acepção programática no uso do termo, há o indicativo de uma proximidade poética pressentida entre seus contemporâneos.
} 
Barrento, de forma criativa, sintetiza esse deslocamento para o sujeito e seus afetos: "passa-se da experimentação para a experiência, do poema sem sujeito para formas de uma 'nova subjetividade' (como também se lhe chamou nos anos 70 alemães)" (BARRENTO, 2000). A lembrança do movimento Neue Subjektivität é ilustrativa desta inflexão no campo literário ocidental - termos como Alltagslyrik (lírica do cotidiano) e Neue Innerlichkeit (nova interioridade) poderiam ser aplicados aos pares portugueses. Poetas como Nicolas Born mostraram-se empenhados em abandonar o que consideravam artificial, ornamental no discurso lírico em defesa de uma dicção francamente afetiva e arraigada na simplicidade das experiências cotidianas.

A respeito da poesia francesa do mesmo período, sob as etiquetas "novo lirismo" ou "lirismo crítico", Jean Michel-Maulpoix assinala que "ce retour du/au lyrisme se situe pour une part dans un déplacement de l'attention de la page blanche (ou de la table d'écriture) vers le monde" ou "l'affirmation renouvelée d'une interdépendance étroite entre l'écriture et la vie" (MAULPOIX, 1998, p. 120, grifo nosso) ${ }^{6}$. É o tipo de afirmação recorrente em declarações públicas de Al Berto - em 1987, para o Jornal de Letras, diz: "a escrita é o resultado de um lento e doloroso trabalho: esse de viver" (AL BERTO, 1987, p. 3, grifo nosso); dez anos depois, para o Diário de Notícias, defende: "Não se fazem poemas sem viver (...) Não acredito em poetas de apartamento" (AL BERTO, 1997, p. 32). Algo semelhante está dito em seus Diários: "Escrever, pelo menos no que me diz respeito, é um projecto que assenta em grande parte, na maneira como estou na vida, na maneira como me vou dimensionando com o que me rodeia” (D, p. 88).

Se nos referimos a esse estreitamento do vínculo entre vida e arte, não se pode ler, entretanto, essa poesia sob uma ótica que pressuponha, por exemplo, a identidade entre autor e obra. Em outras palavras, "recuperada a noção de subjetividade, ela é agora uma subjetividade diferente - menos centrada sobre cada sujeito ou, se quisermos, mais passiva e anônima, irremediavelmente dispersa e sem lugar" (AMARAL, 1988, p. 162, grifo nosso). A avaliação de Pinto do Amaral não se refere especificamente a Al Berto, mas nos parece perfeitamente cabível. De imediato, poderíamos ser levados a recusar, por contraditório, "passiva" e "anónima" como adjetivos para descrever a subjetividade manifesta em sua lírica, sobretudo quando muito se repete o alto teor "confessional", "autobiográfico" e "narcísico" do poeta.

\footnotetext{
6 “esse retorno do/ao lírismo se situa, por um lado, no deslocamento da atenção para a página branca (ou para a mesa de escritura) em direção ao mundo" e "a afirmação renovada de uma interdependência estreita entre a escritura e a vida" [versão nossa]
} 
Sobre isso, também em seus Diários, o poeta registra o "desinteresse que tenho pela minha vida passada fora do âmbito do trabalho poético feito. Já disse tudo. Há muito pouco a acrecentar. Entrei num limbo semi-obscuro" (D, p. 332, grifo nosso). É lugar de intermédio, de disputa entre luz e sombra, em que concorrem a afirmação e a negação do sujeito, os desejos de encher-se dos afetos e deles se esvaziar. Esse nó irresolúvel, no seio na poesia de Al Berto, é prova outra dos paradoxos contemporâneos relativos às questões de um $E u$ que se apresenta tão-somente de forma precária e tensionada.

Rigorosamente considerado, recuperar a noção de subjetividade não denota um regresso do autor, pois, e a advertência é de Manuel de Freitas, este "sempre esteve lá (o peso exacto do deíctico é que é variável, podendo corresponder - como em Mallarmé - a uma forma de ausência)" (FREITAS, 1999, p. 92, grifo do autor). É preciso bem salientar: vocábulos tais como "regresso", "retorno" e "recuperação", quando utilizados nesse trabalho, referem-se um maior "peso", a uma renovada "tônica" na subjetividade, o que também poderia ser dito sobre o real.

Segundo Martelo, "a tentativa de articular arte e vida nunca estivera, na verdade, ausente. A grande ausência fora, desde Baudelaire, a impossibilidade de articular a arte e a vida-enquanto-presença, e essa ausência de real marca toda a literatura do século XX" (MARTELO, 2007, p. 42, grifo da autora). São diferentes estratégias, diferentes protocolos de leitura. Com vocabulário parecido, Pinto do Amaral assim avalia a poesia produzida na década de 1970, na qual

\footnotetext{
sentimos um mal-estar vital, um desconforto surdo e penetrante que talvez um dia venha a fazer desta curiosa geração [a dos anos setenta] não a da presença, mas a da ausência - ou seja, tomando abrigo sob esta imensa Ausência anunciada pela modernidade, deixou de limitar-se à sua estéril proclamação, procurando encontrar linhas de fuga pessoais que se vêm organizando pela via do recurso à precariedade de pequenas e fragmentárias presenças (AMARAL, 1991, p. 51-52, grifo do autor)
}

Ainda que falemos de um novo vínculo entre o sujeito e a realidade, ele tem de ser entendido de forma problemática e tensionada. As noções de subjetividade e realidade são postas nos termos dos sinais, isto é, de indícios, de fragmentos incapazes de se constituírem de forma estável em um todo. Como aponta Fernando Guimarães a respeito de poema de João Miguel Fernandes Jorge, a linguagem procura privilegiar "os caracteres apagadamente distintivos dos "sinais' que tendem a desconstruir a realidade das coisas" (GUIMARÃES, 2002, p. 157).

Constante de seu espólio, na "Nota biográfica em forma de carta", Al Berto diz: "Por outro lado, parece-me irrelevante esboçar o trajecto duma vida que, sinceramente, eu tantas 
vezes confundo com a vida dos poemas. Assim, seduz-me mais a ideia de abandonar, ao acaso, algumas pistas ao correr desta carta". A ideia que o seduz, a de "abandonar pistas", não parece exclusiva do sujeito, mas de todo o mundus tal qual fundado por sua poesia. (E. 49, cx. 39 , grifo nosso).

É justamente frente a essa realidade cada vez mais esboroada que o novo relevo dado à subjetividade torna-se o recurso, ainda que precário, para escapar das aporias oriundas dos impasses da (autor)representação. Sobre isso, cabe a distinção que Rosa Maria Martelo faz entre desajuste do romântico e o desajuste do contemporâneo: o do primeiro era entre o ser humano e o mundo; o do último está no plano "da permanente virtualização do real, à qual a subjectivação das referências, que conduz à recusa do lirismo abstractizante, procura responder" (MARTELO, 2007, p. 40, grifo nosso).

Avançar nessa evocação aos românticos é bastante produtivo, na medida em que se fala, sobre essa geração, até mesmo em "novo-romantismo" (GUIMARÃES, 2002, p. 159). Em outra oportunidade, no artigo de nome "Modernidade e senso comum: o lirismo nos finais do século XX”, Martelo apresenta uma aguda reflexão sobre o tema, partindo da diferenciação que fizeram os românticos entre poema e poesia. Menciona como exemplo a indagação de Friedrich Schelegel, mantida aqui na tradução francesa aduzida pela autora: "Et que sont-ils [poemas] compares à la poésie sans forme ni conscience qui palpite dans les plantes, rayonne dans la lumière, sourit dans l'enfant, étincelle dans la fleur de la jeunesse, s'embrase dans le cœur aimant des femmes?" (SCHELEGEL, 1800, apud MARTELO, 2003, p. 92). O poema, completa a crítica, deve ser entendido "como uma mediação que lhe dá acesso à experiência idêntica" (MARTELO, 2003, p. 92). A poesia não pode ser comparada ao poema; excede-o.

Contrariamente a essa posição, encontraríamos o entendimento de que poesia existe tão somente nos limites do poema - exemplo disso seria a citada Poesia 61 e sua resistência à decifração de "um sentido para lá do texto, quando esses versos o recusavam e eram apenas fiéis à sua literalidade" (AMARAL, 1991, p. 48, grifos do autor). Esse senso "para lá", negado nos de sessenta, que nos parece expresso nos Diários recém-publicados do poeta sublinhemos o desejo do "fora": "E quase temos vontade de precipitarmos os corpos para fora das palavras. Para fora do tempo que nos cerca, para fora do crepúsculo que nos surpreende, para fora de nós mesmos, para fora...” (D, p. 160, grifo nosso).

\footnotetext{
7 "Literalidade" é pensada como a coincidência entre poema e poesia, "no quadro de uma linguagem de ruptura e de recusa de referencialidade directa" (ibid., p. 48). Julgamos necessário o aparte para que não se confunda justamente com o seu contrário: a "literalidade" de uma poesia de pendor prosaico, colada a um efeito de referencialidade mais imediata, como a do Cartucho e, atualmente, por exemplo, a dos "poetas sem qualidades".
} 
Tendo em mente as inflexões da poesia, essas a que temos aludido na década de 70 , Martelo percebe que

a poesia volta a descoincidir do poema se bem que agora quase sempre se apresente de modo secularizado implicando uma experiência sobretudo emocional e vivencial, tanto mais que esta situação tem agora atrás de si o baudelairiano mergulho do poeta 'flâneur' na multidão citadina (MARTELO, 2003, p. 98).

Lembra ainda que não se trata de uma mudança no público de poesia, mas de um novo tipo de protocolo de leitura, no qual "a experiência do sujeito poético apresenta-se como algo partilhado, ou facilmente partilhável com o leitor" (MARTELO, 2003, p. 101). Ou, como diz Al Berto: "escrevo para sobreviver / como quem necessita partilhar um segredo" (M., p. 541, grifo nosso). Grifemos esse imperativo pela "partilha" ou por um senso de maior comunicabilidade com o leitor.

A alusão à flânerie e ao nexo benjaminiano entre poesia e desolação na cidade está intimamente ligado à marginalidade de poeta, como já o era na veia abjecionista de um Mario Cesariny, por exemplo. Quando Martelo nos fala da experiência poética como "algo de partilhado", refere-se à capacidade dialógica, de estabelecer pontes comunicativas mais libertas - quer pelo seu conteúdo na tematização de comportamentos recalcados pelo conservadorismo salazarista, quer pela sua forma mais próxima à linguagem cotidiana e mais distante do virtuosismo linguístico. Sobre essa linguagem, Fernando J. B. Martinho comenta:

\footnotetext{
assiste-se (...) a uma abertura da poesia, e com toda desinibição, a domínios que até aí lhe tinham estado mais ou menos vedados, ou a que só, com extremos cuidados, podia aludir: o erótico, o escatológico ou, mais latentemente, tudo o que tivesse a marca da marginalidade. (MARTINHO, 1984, p. 20, grifo do autor)
}

Essas questões parecem concentradas e bem exploradas em Pinto do Amaral através da polissemia do "sentido" (AMARAL, 1988, p. 161). Com a expressão, o crítico queria apontar três usos diferentes do vocábulo, os quais desenvolvemos a partir do já exposto: a) as linhas de sentido: a primazia do significado sobre o significante e, com isso, a baixa disposição ao que pareça regramentos e hermetismos, o afã comunicativo e dialógico observável na constate evocação de um Tu; b) o mais sentido: o retorno de uma dicção sentimental, excessiva por vezes, avessa às generalizações da impessoalidade e pensada na relação entre experiência e poesia - em especial, na lírica amorosa; e c) sentidos do corpo: o deslocamento de uma poesia autocentrada para outra de expressão dos afetos, ligada à experiência do corpo, a um erotismo da escrita e à recusa de uma assepsia ou decoro temático. Acerca deste último aspecto, é interessante chamarmos novamente as palavras de Joaquim Manuel Magalhães, para quem, nessa poesia, "irrompe uma explicitação dos lugares do corpo, 
uma afirmação dos desejos e das intenções, uma narração dos confrontos com a ordem do lugar, ligados a um discurso mais empenhado em declarar do que em sintetizar ou visualizar" (MAGALHÃES, 1981, p. 258).

Esse "retorno do sentido", por outras vias, é examinado por Jean-Claude Pinson a partir de analogia feita com as artes plásticas ao meditar sobre a poesia francesa contemporânea. O crítico recorda o comentário feito por Clement Greenberg sobre pintura abstrata no modernismo, que colocou em xeque o ilusionismo pictural clássico - isto é, o quadro a funcionar como uma "janela". Pinson, então, propõe o conceito de "poésie-rideau" [poesia-cortina], ou seja, aquela consciente de sua impossibilidade de contato com o mundo, com o além da "janela". A poesia seria, segundo a leitura de Hugo Friedrich retomada por Pinson, fundamentalmente abstrata e, portanto, calcada nas três célebres proposições características da estrutura da lírica moderna: desrepresentação, despersonalização e incomunicabilidade.

A passagem para o contemporâneo, para o crítico francês, é marcada pelo abandono da "cortina", do princípio abstracionista, isto é, de "son essence puremente "textuelle"" (PINSON, 2002, p. 142) - "essência textual" entendida como "la mesure où le poème instaure en absolu l'espace textual qui est le sien" (PINSON, 2002, p. 138), que nada mais faz do que repetir a supracitada coincidência entre poesia e poema. Para ilustrar o retorno ao real perspectivado pela subjetividade, o crítico utiliza-se da imagem de uma "janela veneziana": "le poème ne fonctionne donc pas comme um rideau bouchant toute vue sur le monde. Il est plutôt comme un store vénitien qui en filtre la lumière selon des angles variés" (PINSON, 2002, p. 147) ${ }^{8}$.

Ainda na tentativa de caracterizar, permitam a digressão. Falávamos, en passant, das críticas alemã e francesa, sensíveis às mesmas alterações em suas tradições poéticas. No caso da poesia americana, esse embate é anterior - data das décadas de 50 e 60 -, mas vale a lembrança, sobretudo por conta de um curioso e provocativo comentário feito por Robert Lowell. Quando do recebimento do National Book Award, em 1960, o poeta assim descreveu os grupos divergentes da época - a saber, os Beats, Confessionals e os da Black Mountain School, de um lado; os formalistas da New Critical, de outro:

two poetries are now competing, a cooked and a raw. The cooked, marvelously expert, often seems laboriously concocted to be tasted and digested by a graduate seminar. The raw, huge blood-dripping gobbets of unseasoned experience are dished

\footnotetext{
8 “sua essência puramente "textual"”, "a medida em que o poema instaura em absoluto o espaço textual que é o seu" e "o poema não funciona, então, como uma cortina tapando toda a vista para o mundo. Ele é, muitas vezes, como uma janela veneziana que filtra a luz segundo seus vários ângulos" [versões nossas]
} 
up for midnight listeners. There is a poetry that can only be studied, and a poetry that can only be declaimed, a poetry of pedantry, and a poetry of scandal. (LOWELL, 1960, apud RAMAZANI et al., 2003, p. xlix; grifo nosso)

O próprio Lowell reconhece, em seguida, os excessos maniqueístas do retrato. De qualquer maneira, se lhe faltam matizações imprescindíveis, a distinção pode ser ao menos operacional: de um lado, a poesia focada em seu próprio fazer, no labor; de outro, na vida, na unseasoned experience. É possível pensarmos ainda nos diferentes horizontes de expectativa implicados em cada poética: a primeira, to be studied, é cerebral, rigorosa; a outra, to be declaimed, é sensitiva, marginal. Al Berto tendia claramente para o segundo grupo, como confidencia em entrevista televisiva de 1994 - transcrita por Golgona Anghel: "Há um momento em que me sinto quase compelido a ler as coisas em voz alta e leio e mesmo acontece de gravá-los para depois me ouvir" (ANGHEL, 2006, p. 15). Sobre isso, como bem pontuou Anghel, havia na poesia de Al Berto a exigência de uma voz.

A dicotomia proposta por Lowell já foi, de alguma maneira, expressa por outros pares binários ${ }^{9}$ ao longo da história da poesia: órfico e hermético, visionário e artífice, inspirado e artesão, forma e força, etc. Todos remontam, como demonstrou levantamento de Manuel Gusmão, "a noção platónica do entusiasmo que rapta o poeta ou o rapsodo, e a noção aristotélica do poeta como fazedor".

O próprio Gusmão propõe "dois paradigmas da imaginação científica: o cristal e a chama" (2010, p. 352; grifos do autor). O primeiro remete-nos ao trabalho de lenta sedimentação, passível de exame minucioso, microscópico; enquanto o segundo, à dimensão do verbo mais orgânico, intensificado e menos apto à decomposição analítica.

Acreditamos que sob esse viés também se pode entender a recuperação, por JeanClaude Pinson, dos conceitos schillerianos de poesia ingênua e sentimental. Nas palavras do filósofo alemão,

ao poeta ingênuo, a natureza concedeu o favor de sempre atuar como uma unidade indivisa (...) e de expor a humanidade na realidade segundo seu conteúdo inteiro[;] (...) ao sentimental, emprestou o poder ou, antes, dotou-o de um vivo impulso para reestabelecer por si mesmo aquela unidade nele suprimida por abstração (SCHILLER, 1991, p. 88).

O tradutor Márcio Suzuki, em prefácio da edição brasileira, comenta que a obra ingênua "parece não guardar vestígio de toda a habilidade técnica empregada em produzi-la"

\footnotetext{
${ }^{9}$ Já fora ressalvado anteriormente, mas fica o reforço: são dicotomias operativas, que, embora nos ajudem a perceber certas características poéticas, não se prestam a categorizar de modo estanque este ou aquele autor. Se tais pares funcionam como pontos de partida, temos por horizonte o exame de hibridismos e infiltrações, pelos quais se observam diferentes tônicas, modulações e deslocamentos.
} 
(SUZUKI, 1991, p. 17); uma obra sentimental, por sua vez, é marcada pela "atividade reflexionante", mas "não apenas reflete, também convida o leitor a percorrer o mesmo fio de raciocínio em relação ao objeto" (SUZUKI, 1991, p. 27) - o que, no contexto da poesia moderna, levou à constante atividade metalinguística.

Assim sendo, o polo sentimental seria representado pelo rompimento com o real, enquanto a tendência aqui abordada, a do "regresso" a ele, exibiria o

\begin{abstract}
désir de 'naïveté', désir de retrouver le regard de l'enfance, désir d'une limitation de l'ironie, de sa négativité sans fin (négativité que est celle du langage lui-même), désir non pas d'adhésion à l'ordre du monde mais d'adhérence à sa concrétude et à sa contingence afin d'en pouvoir capter la dimension épique ou lyrique nouvelle (PINSON, 2002, p. 145, grifo do autor) ${ }^{10}$.
\end{abstract}

O contemporâneo põe-se, dessa maneira, no centro da tensão dialética entre duas linhas de força: "si la poésie contemporaine ne cesse de s'autoréfléchir, (...) elle a cessé cependant de refouler son désir d'une 'naïveté' seconde." (PINSON, 2002, p. 145) ${ }^{11}$. O poeta, assim, não ignora a reflexão linguístico-filosófica acerca do texto e da linguagem (que orientou a poesia de pendor modernista até suas expressões mais recentes, a Poesia 61 e a PoEx); ele vive, nas palavras de Pinto do Amaral, a "exaustão de um impasse" e "já que ele existe, evitemos enfatizá-los a cada instante, procurando, isso sim, fingir que dele nos esquecemos, para melhor supor que o soubemos ultrapassar" (AMARAL, 1991, p. 50).

Embora o crítico não afirme, sequer sugira, talvez "fingir esquecimento" não constitua a melhor expressão pela aparente ideia de resolução. Preferimos falar na coabitação conflituosa de dois princípios, campo de oximoros. Diana Klinger, ao analisar a prosa contemporânea brasileira, constata que seu corpus não se apresenta como "expressão de uma singularidade dona de si e da escrita" e esboça a seguinte hipótese: "estes textos parecem responder ao mesmo tempo e paradoxalmente ao narcisismo midiático e à crítica do sujeito" (KLINGER, 2007, p. 26; grifo da autora).

\title{
Dois poemas de Al Berto
}

Gostaríamos de passar em análise, mais detidamente, pelo material poético de $\mathrm{Al}$ Berto considerado a partir do escopo teórico que procuramos delinear. São dois poemas

\footnotetext{
10 “desejo de uma 'ingenuidade', desejo de encontrar o olhar da infância, desejo de limitar a ironia e sua negatividade sem fim (negatividade que é aquela da linguagem mesma), desejo não mais de adesão à ordem do mundo, mas de aderência a sua concretude e sua contingência afim de poder captar a nova dimensão épica ou lírica" [versão nossa]

11 "se a poesia contemporânea não cessa de se autorrefletir, (...) ela cessa contudo de suprimir seu desejo de uma 'ingenuidade' outra.” [versão nossa]
} 
retirados do livro Salsugem; todos fazem parte da seção "Quinta de Santa Catarina (fragmentos de um diário)".

A primeira pergunta que enfrentamos, antes mesmo de adentrarmos os poemas propriamente, é sobre a relação entre vida e poesia, já indiciada pelo parêntese "(fragmentos de um diário)" e pela utilização, como veremos, de anos como títulos. A obra de Al Berto é permeada pelos ditos gêneros autobiográficos (autobiografia, diário íntimo, memórias, correspondência, etc.). Encontraríamos igualmente outro exemplo na série de "diários" $O$ Medo inclusos em seu "trabalho poético" - o que não ocorre, por exemplo, com a narrativa Lunário. Manuel de Freitas, ao estudar os três volumes (pseudo)diarísticos, percebe a coexistência de apontamentos prosaicos, característicos do diário, e de momentos assumidamente líricos. Isso põe em discussão a pertinência da taxonomia dos gêneros e levamo-nos, antes, a pensar em estratégias de hibridização e simulação das modalidades autobiográficas "canônicas". De qualquer forma, "o que parece não oferecer dúvida" concluímos com Freitas - "é a preferência (quando não obsessão) por uma escrita autobiográfica" (FREITAS, 2005, p. 23, grifo do autor).

O primeiro deles (M, p. 278) enceta uma descrição ilustrativa do "paradigma narrativo", que nos sublinhava Barrento (2000), e contrária ao "vocabulário mínimo", à “condensação da linguagem poética” (GUIMARÃES, 2002, p. 36), que Guimarães percebia, genericamente, na poesia de 60 :

\section{$8 . / 1980$}

sentado numa cadeira os pés enterrados na areia o homem dedilha uma guitarra estou longe dele não consigo ouvir a música que suspeito ter a cumplicidade das águas

é um homem só aquele sedutor do tempo infinito das praias e não possui espelho onde possa amar o seu reflexo olho-o de muito longe pressinto os apitos roucos dos navios carregados de petróleo esses barcos de morte mais parecem flutuantes cidades quando à noite se iluminam... o homem levanta-se um bando de gaivotas pardas sobrevoa o areal... vejo-o caminhar com a cadeira na mão até desaparecer por trás duns barracões em zinco... além ao fundo para lá dos rochedos dinamitados... ele a cadeira e a guitarra

o areal é apenas uma sensação de queda só eu permaneço aqui... frente ao mar espero que a sétima onda me traga a frescura da música tantas noites inaudível

fico atento à textura óssea das conchas enquanto a memória esboça os passos do homem desaparecido 


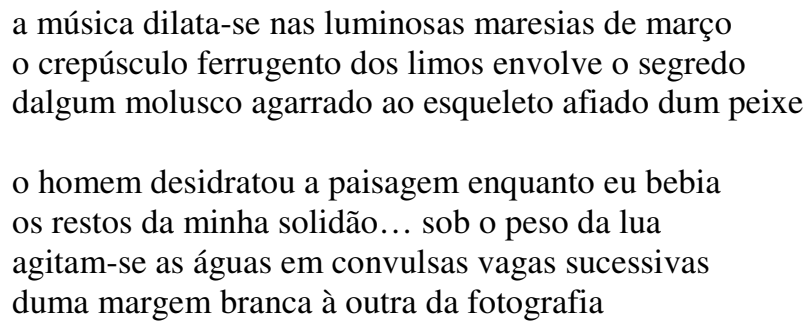

À primeira vista, trata-se de uma paisagem que se quer sem pudores quanto ao seu desenvolvimento descritivo e de fácil localização por seus índices referenciais - já não bastasse a menção à "Quinta de Santa Catarina", os "navios carregados de petróleo" e os "rochedos dinamitados" dão conta das atividades petroleiras e mineradoras na cidade portuária de Sines, onde Al Berto viveu parte da vida.

Os personagens do retrato são dois: um músico que toca sua guitarra e um poeta que o observa. Os paradigmas estéticos de ambos, de alguma forma, são postos em contraposição. Se partirmos do imaginário que cercam esses artistas, o primeiro está ligado à abstração típica da música: sua arte é, por isso, menos referencial, menos ancorada em uma historicidade ("tempo infinito"). O poeta, por sua vez, é o que "possui espelho onde possa amar o seu reflexo" e, destarte, circunscreve seu fazer artístico aos limites do sujeito, ao seu espaço e tempo específicos. Acreditamos que esta antítese ressurge, ao fim do poema: "o homem desidratou a paisagem enquanto eu bebia / os restos da minha solidão".

O músico, sujeito solar, ao se retirar no entardecer, abandona o poeta, noturno, que "permanece só" e nostálgico a esperar, na "sétima onda" - e sete é um número de criação, das notas, das cordas da lira, e, assim, pode se referir à arte -, o retorno da "frescura da música".

A música guarda um vínculo estreito com a natureza, sobretudo com a água: ela é "cúmplice das águas", "dilata-se nas luminosas maresias" e, sem ela, a "paisagem desidratase". Martelo compreende a inexpugnável sensação de ausência do poeta como fruto de sua situação urbana, pois ele "se afastara da Natureza e perdera a condição de experimentar a relação entre a experiência subjectiva e experiência do mundo em condição de intrinsecidade". Lembra a crítica ser "sintomático" que "os grandes poetas da epifania tenham permanecido, de algum modo, poetas da Natureza" (MARTELO, 2007, p. 26). A música, portanto, sintetiza uma abertura, uma abolição de fronteiras - do tempo, do indivíduo, do figurativo -, enquanto o poeta fica "atento à textura óssea das conchas" - no que a imagem sugere de fechamento em si e de, em termos fotográficos, uma focagem cuja profundidade de campo é cada vez menor, ou seja, vê-se cada vez mais o detalhe mínimo e menos a paisagem, o horizonte. 
Já que evocamos a fotografia, retomemos aquele pequeno núcleo narrativo inicial: um sujeito a observar outro na praia que, em dado momento, se retira. O último verso, todavia, coloca em xeque a possibilidade de leitura como mera descrição de cena: "duma margem branca à outra da fotografia”. Alguns versos, se relidos sob esta perspectiva, ganham outra conotação - por isso, a repetição do aviso: "estou longe dele não consigo ouvir a música" e "olho-o de muito longe". Esse homem é visto a partir da memória, "que esboça os passos do homem desaparecido".

Dessa maneira, o que poderia ser uma peça de descritivismo convencional distanciase de qualquer principio mimético dado o número de filtros - da fotografia, da memória, da própria poesia - entre o ato e seu registro. As reviravoltas que descentram as balizas referenciais, ao mesmo tempo em que delas se apropriam, serão características da poesia albertiana e estão presentes também no próximo poema a ser analisado:

\section{7./ 1980}

ao coração da terra desce o luar

pressinto as quilhas dos navios romperem a cinza da manhã

(escrevo um diário

fumo

bebo

aborreço-me)

atravesso o relâmpago esquecido na veia óssea da noite reconheço o sítio onde os corpos já não se encontram

(estou sentado numa cadeira de lona

olho o mar

é tudo o que sei fazer

olhar o mar e não pensar)

tocámo-nos apesar do que violentamente ficou dito

agora só vens no veludo manchado dos sonhos pérola mastigada na queimadura da boca ou quando arrumo as fotografias surges inesperadamente do fundo da gaveta com o perfume áspero da madeira

anoitece...o ar está impregnado de iodo um fio de luz define o rosto contra a parede a cal retém o sussurrar antigo dos corpos e quando a manhã se aproxima da janela a memória seca ou dorme para sempre

\section{(a boca}

talvez fosse a boca de A. surgindo sobre a folha de papel respirando)

ainda continuei a escrever durante alguns dias sem grande rigor é certo...uma aranha movia-se nos vidros a melancolia trepava ao cimo das árvores assustando os insectos da folhagem e os pássaros esperei o sono com suas pálpebras vegetais e a paixão 
apareceu naquele rosto orvalhado abrindo-se enfim

à constelação doutro rosto sujo de tinta e de palavras

Novamente, um dado significativo está relacionado ao fôlego declamatório dum poema que já se alonga, se comparado ao comedimento retórico dos poetas da geração anterior - excluídos Ruy Belo e Herberto Helder dos quais Al Berto é devedor nesse aspecto. Como dito no poema, aqui não interessa o "grande rigor" da escrita, já que a opção é, em certo sentido, por uma raw poetry - ou pela criação de um efeito dela -, na classificação de Lowell: "continuo sentado / escrevo a desordem urgente das horas..." (M, p. 270).

Através do que Prado Coelho chamou de "indiscriminação distraída" (COELHO, 1988, p. 131), a primeira estrofe oscila entre passagens de maior voltagem lírica, de maior exploração imagética - como em "atravesso o relâmpago esquecido na veia óssea da noite" e outras mais referenciais, descritivas - aquelas entre os dois primeiros parênteses ("fumo/bebo" ou "estou sentado numa cadeira de lona"). Como se, contrapontisticamente, o discurso poético fosse infiltrado por outro, cotidiano e enraizado no tempo da ação, que parece indicar o que o sujeito faz enquanto se põe a escrever.

Em seguida, aparecem elementos que recuperam um Tu perdido: os sonhos e as fotografias. Interessante notar como tais estopins da memória aparecem carregados de uma ancoragem referencial forte: o "veludo manchado" ou o "perfume áspero da madeira". Essa atenção para detalhes mínimos do ambiente doméstico (presente também em "uma aranha movia-se nos vidros") é basilar para a percepção dessa realidade em ruínas, em fragmentos. Ainda sobre o ato de rememoração, gostaríamos também de frisar como ele é marcado temporalmente pela noite, filiando-se à tradição que remonta ao Romantismo: "e quando a manhã se aproxima da janela / a memória seca ou dorme para sempre”.

O cenário doméstico é representado metonimicamente: "o fundo da gaveta", "a janela", "aranha movia-se nos vidros". Qual comentado, o espaço não está submetido a uma descrição mimética, mas à contaminação pelo sujeito e por seus afetos - como em "perfume áspero da madeira”, em que uma percepção sensorial compreende a adjetivação emocional, ou como explica em duas passagens: "retenho ainda os mais íntimos desejos de me confundir com a paisagem" (M, p. 166) e "o meu rosto - pensou - está lá fora, substituiu a paisagem" (M, p. 375). Por isso, sua melancolia é entidade corpórea, um bicho à espreita; as paredes da casa "retêm o sussurrar antigo dos corpos" na alvura da cal, que é também sugestão ao branco da página e ao "reter" da escrita.

O jogo de vozes torna-se mais ambíguo e complexo ao passar das estrofes. Movimento semelhante notou Carlo Vittorio Cattaneo, ao comentar outro poema em resenha 
para Salsugem: a princípio não se distingue "entre poesia e feuilleton", mas tão logo percebemos que a facilidade é enganosa e somos levados a questionar, afinal, de que realidade trata o poeta (CATTANEO, 1986, p. 90). O último parêntese abandona sua conotação mais corriqueira e fala de uma espécie de nascimento do Tu, "a boca de A.", através da escrita, que é, então, mecanismo de recuperação/reconstrução do Outro, não em sua impossível completude, mas através "doutro rosto sujo de tinta e de palavras" - imagem que reforça a ideia de um "parto lírico", do primeiro respiro de ânimo.

O esforço de inscrever/construir o real no estético e a consciência da transposição problemática serão recorrentes nos poemas: jamais será um domínio estável e, no entanto, jamais será abandonado. O primeiro poema da sessão "Eras novo ainda" tem uma passagem bem conseguida do efeito "ao vivo" que busca criar a impressão de coincidência entre os atos da escrita e de leitura, isto é, como se o leitor testemunhasse a ação: "debruço-me para a velha mesa encerrada / uma aranha arrasta-se sobre a folha de papel / espeto-lhe o aparo... escrevo / a crueldade das palavras que te cantam" (M, p. 291). A crueldade, causada pela ausência do Outro, é plasmada no poema, no momento de sua escrita, pela incorporação "material" - por assim dizer - de outra crueldade, aquela de matar o animal na própria página.

\section{Conclusão}

$\mathrm{O}$ artigo procurou demonstrar as principais características da poesia portuguesa contemporânea na década de 70 a partir do caso exemplar da obra de Al Berto. Claro está que não pretendemos em nenhum momento meramente enquadrar a poesia albertiana, mas apercebermo-nos de como o poeta esteve em consonância com a tendência dominante de seu tempo a partir de suas questões, de suas particularidades. As características foram aqui evocadas não apenas para desenhar um quadro panorâmico dessa geração, mas também - e sobretudo - para matizá-lo, problematizá-lo em seus impasses e paradoxos.

Nesse sentido, recuperemos a quadra com que abrimos esse artigo: "da humidade antiga do eremitério ergue-se / a sageza e a sabedoria que foi abandonando / à laboriosa travessia da vida / à lentíssima decifração do medo e dos sinais” (M, p. 505). A poesia abandonou a sageza em nome da vinculação da vida, de sua travessia. E, sendo estrada que se atravessa, impôs-se a ela o lugar de perene movência, de indecisão: "a estrada é uma ideia que nunca acaba, nada tem a ver com a quilometragem a percorrer ou percorrida. A estrada é uma concepção que não se realiza. Não é um princípio nem fim, é apenas meio, que é sempre o lugar onde me sinto" (D, p. 79). 


\section{Referências}

AL BERTO. O Medo (trabalho poético 1974-1997). Lisboa: Assírio \& Alvim, 2009.

Diários. Porto: Assírio \& Alvim, 2012.

Sou um homem insone. Jornal de Letras, Lisboa, 19 out. 1987. p. 3

Dor e silêncio das ruas vazias. Diário de Notícias, Lisboa, 26 abr. 1997. p. 32

ANGHEL, Golgona. Al Berto Oral. In: AL BERTO. O último coração do sonho. Vila Nova de Famalicão: Quasi Edições, 2006. p. 13-31

AMARAL, Fernando Pinto do. O mosaico fluido. Lisboa: Assírio \& Alvin, 1991.

O regresso ao sentido - anos 70/80. A Phala - um século de poesia. Lisboa: Assírio \& Alvim, 1988. p. 158-167.

BARRENTO, João. Um quarto de Século de Poesia Portuguesa. Semear, Rio de Janeiro, n. 4, 2000. Disponível em: http://www.letras.puc-rio.br/unidades\&nucleos/catedra/revista/ 4Sem_19.html Acesso em: 15 jun. 2013.

CATTANEO, Carlo Vittorio. [Recensão crítica a 'Salsugem', de Al Berto]. Colóquio/Letras, Lisboa, n. 91, 1986. p. 90-91.

COELHO, Eduardo Prado. A noite do mundo. Lisboa: IN-CM, 1988.

FREITAS, Manuel de. Me, Myself and I. Lisboa: Assírio \& Alvin, 2005.

A noite dos espelhos. Lisboa: frenesi, 1999.

FRIEDRICH, Hugo. Estrutura da lírica moderna: (da metade do século XIX a meados do século XX). São Paulo: Livraria Duas Cidades, 1991.

GUIMARÃES, Fernando. A Poesia Contemporânea Portuguesa. Vila Nova de Famalicão: Edições Quasi, 2002.

GUSMÃO, Manuel. Tatuagem \& Palimpsesto. Lisboa: Assírio \& Alvim, 2010.

JÚDICE, Nuno. Viagem por um século de literatura portuguesa. Lisboa: Relógio D’água, 1997.

[Carta] In: DIAS, Joaquim Cardoso (org.). Dez cartas para Al Berto. Vila Nova de Farmalicão: Quasi, 2007.

KLINGER, Diana. Escritas de si, escritas do outro: o retorno do autor e a virada etnográfica. Rio de Janeiro: 7Letras, 2007

MAGALHÃES, Joaquim Manuel. Os dois crepúsculos. Lisboa: A Regra do Jogo, 1981.

MARTELO, Rosa Maria. Modernidade e senso comum: o lirismo nos finais do século XX. Cadernos de Literatura Comparada, Porto, n. 8/9, 2003. p. 89-104 
Vidro do mesmo vidro. Porto: Campo das Letras, 2007.

MARTINHO, Fernando J. B. Dez anos de literatura portuguesa (1974-1984): poesia. Colóquio/Letras, Lisboa, n. 78, 1984. pp.17-29

MAULPOIX, Jean-Michel. La poésie comme l'amour. Paris:Mercure de France, 1998.

PINSON, Jean Claude. Sentimentale et naïve. Paris: Champ Vallon, 2002.

RAMAZANI, Jahan et al. (orgs.). The Norton anthology of modern and contemporary poetry. v. 1. New York: London: W. W. Norton, 2003. 2v.

REIS, Carlos. História Crítica da Literatura Portuguesa. Do Neo-Realismo ao PostModernismo. Lisboa: São Paulo: Verbo, 2005.

RILKE, R. M. Cartas a um jovem de poeta. Rio de Janeiro: Editora Globo, 1986.

SASAKI, Leonardo de Barros. Decifrar os sinais de intimidade: leituras de Al Berto. São Paulo: Universidade de São Paulo, 2012. (Dissertação de Mestrado em Letras)

SCHILLER, Friedrich. Poesia ingênua e sentimental. (trad. e pref. Márcio Suzuki). São Paulo: Iluminuras, 1991.

SUZUKI, Márcio. Prefácio. In: SCHILLER, Friedrich. Poesia ingênua e sentimental. (trad. e pref. Márcio Suzuki). São Paulo: Iluminuras, 1991.

TODOROV, Tzvetan. Theories of Symbol. New York: Cornell University Press, 1982.

[Recebido em junho de 2013 e aceito para publicação em novembro de 2013]

\section{Notes on Portuguese poetry of the 70s: the case of Al Berto}

Abstract: This article proposes to debate in general terms the Portuguese contemporay lyric, especially the one written in the 70s, using the exemplary case of Al Berto. Among the topics discussed are: the relationship between poetry and reality, the attempt to return to the real albeit precarious, or rather, in its own precariousness -, the declaratory and dialogical nature poetry, its more affectionate and less virtuosistic diction; the non-coincidence between poem and poetry - some call it "new romanticism"; renewed - and problematic - linking/constitution of the poetic subject; and disinhibition of themes. For this matter, we recover fundamental critical readings not only for the understanding of Portuguese contemporary production as well as for the discussion, in parallel, of the same tendencies in other traditions. Finally, we specifically developed the analysis of two poems by Al Berto in order to demonstrate the theoretical topics pointed before.

Keywords: Poetry Portuguese contemporary. Al Berto. Real. Subjectivity. Affects

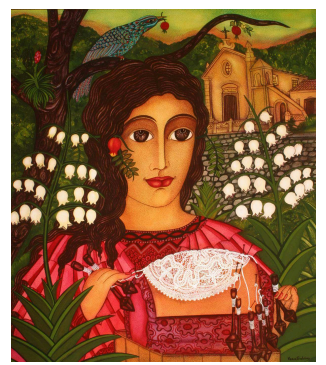

